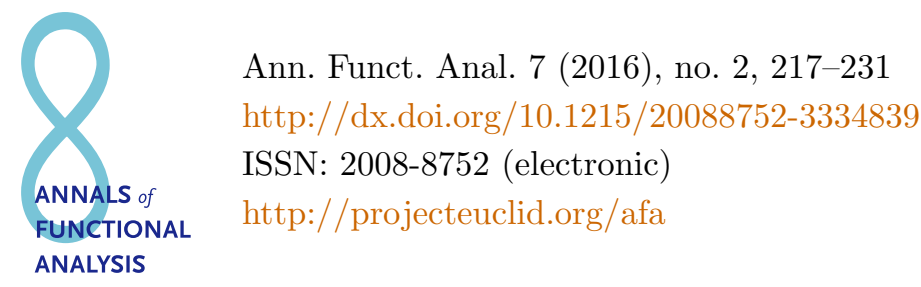

\title{
SCREEN TYPE PROBLEMS FOR ANISOTROPIC PSEUDO-MAXWELL'S EQUATIONS
}

\author{
OTAR CHKADUA,${ }^{1}$ ROLAND DUDUCHAVA,${ }^{2}$ and DAVID KAPANADZE ${ }^{3 *}$ \\ Dedicated to Professor Anthony To-Ming Lau \\ Communicated by Gradimir V. Milovanovic
}

\begin{abstract}
We investigate screen-type boundary value problems for anisotropic pseudo-Maxwell's equations. It is shown that the problems with tangent traces are well posed in tangent Sobolev spaces. The unique solvability result is then obtained by using a potential method and the coercivity result of Costabel for the bilinear form associated with the pseudo-Maxwell's equation.
\end{abstract}

\section{IntRoduction}

The study of boundary value problems in electromagnetism naturally leads us to the pseudo-Maxwell's equations with inherited tangent boundary conditions, which are in some sense nonstandard for the system of elliptic equations (see works of Buffa, Costabel, Christiansen, Dauge, Hazard, Lenoir, Mitrea, Nicaise and others). Indeed, let us consider the time-harmonic Maxwell equations in an anisotropic domain $\Omega \subset \mathbb{R}^{3}$,

$$
\left\{\begin{array}{l}
\operatorname{curl} \mathbf{H}+i \omega \varepsilon \mathbf{E}=0, \\
\operatorname{curl} \mathbf{E}-i \omega \mu \mathbf{H}=0 .
\end{array}\right.
$$

Here, the vector-functions $\mathbf{E}=\left(E_{1}, E_{2}, E_{3}\right)^{\top}$ and $\mathbf{H}=\left(H_{1}, H_{2}, H_{3}\right)^{\top}$ denote the scattered electric and magnetic fields, $\omega$ is the frequency, and the corresponding

Copyright 2016 by the Tusi Mathematical Research Group.

Received Mar. 31, 2015; Accepted May 12, 2015.

${ }^{*}$ Corresponding author.

2010 Mathematics Subject Classification. Primary 35J25; Secondary 35C15, 47F05.

Keywords. screens, pseudo-Maxwell equations, integral representation, potential theory. 


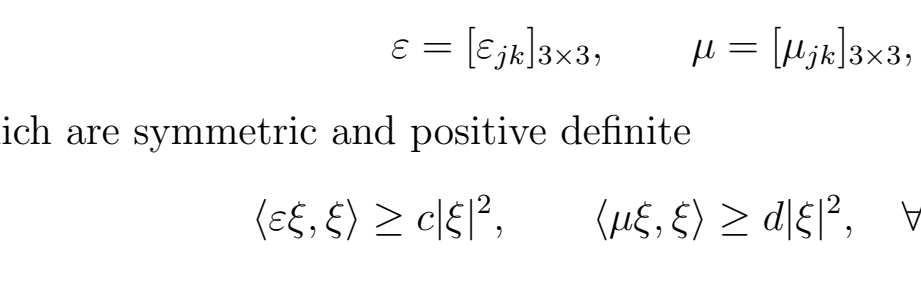

\title{
SCREEN TYPE PROBLEMS FOR ANISOTROPIC PSEUDO-MAXWELL'S EQUATIONS
}

\author{
OTAR CHKADUA,${ }^{1}$ ROLAND DUDUCHAVA,${ }^{2}$ and DAVID KAPANADZE ${ }^{3 *}$ \\ Dedicated to Professor Anthony To-Ming Lau \\ Communicated by Gradimir V. Milovanovic
}

\begin{abstract}
We investigate screen-type boundary value problems for anisotropic pseudo-Maxwell's equations. It is shown that the problems with tangent traces are well posed in tangent Sobolev spaces. The unique solvability result is then obtained by using a potential method and the coercivity result of Costabel for the bilinear form associated with the pseudo-Maxwell's equation.
\end{abstract}

\section{IntRoduction}

The study of boundary value problems in electromagnetism naturally leads us to the pseudo-Maxwell's equations with inherited tangent boundary conditions, which are in some sense nonstandard for the system of elliptic equations (see works of Buffa, Costabel, Christiansen, Dauge, Hazard, Lenoir, Mitrea, Nicaise and others). Indeed, let us consider the time-harmonic Maxwell equations in an anisotropic domain $\Omega \subset \mathbb{R}^{3}$,

$$
\left\{\begin{array}{l}
\operatorname{curl} \mathbf{H}+i \omega \varepsilon \mathbf{E}=0, \\
\operatorname{curl} \mathbf{E}-i \omega \mu \mathbf{H}=0 .
\end{array}\right.
$$

Here, the vector-functions $\mathbf{E}=\left(E_{1}, E_{2}, E_{3}\right)^{\top}$ and $\mathbf{H}=\left(H_{1}, H_{2}, H_{3}\right)^{\top}$ denote the scattered electric and magnetic fields, $\omega$ is the frequency, and the corresponding

Copyright 2016 by the Tusi Mathematical Research Group.

Received Mar. 31, 2015; Accepted May 12, 2015.

${ }^{*}$ Corresponding author.

2010 Mathematics Subject Classification. Primary 35J25; Secondary 35C15, 47F05.

Keywords. screens, pseudo-Maxwell equations, integral representation, potential theory. 


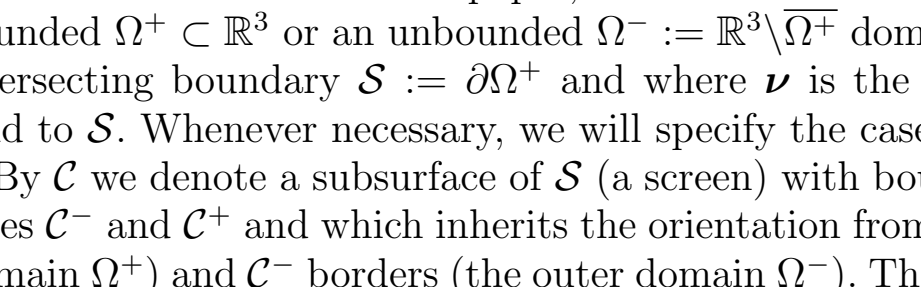

\title{
SCREEN TYPE PROBLEMS FOR ANISOTROPIC PSEUDO-MAXWELL'S EQUATIONS
}

\author{
OTAR CHKADUA,${ }^{1}$ ROLAND DUDUCHAVA,${ }^{2}$ and DAVID KAPANADZE ${ }^{3 *}$ \\ Dedicated to Professor Anthony To-Ming Lau \\ Communicated by Gradimir V. Milovanovic
}

\begin{abstract}
We investigate screen-type boundary value problems for anisotropic pseudo-Maxwell's equations. It is shown that the problems with tangent traces are well posed in tangent Sobolev spaces. The unique solvability result is then obtained by using a potential method and the coercivity result of Costabel for the bilinear form associated with the pseudo-Maxwell's equation.
\end{abstract}

\section{IntRoduction}

The study of boundary value problems in electromagnetism naturally leads us to the pseudo-Maxwell's equations with inherited tangent boundary conditions, which are in some sense nonstandard for the system of elliptic equations (see works of Buffa, Costabel, Christiansen, Dauge, Hazard, Lenoir, Mitrea, Nicaise and others). Indeed, let us consider the time-harmonic Maxwell equations in an anisotropic domain $\Omega \subset \mathbb{R}^{3}$,

$$
\left\{\begin{array}{l}
\operatorname{curl} \mathbf{H}+i \omega \varepsilon \mathbf{E}=0, \\
\operatorname{curl} \mathbf{E}-i \omega \mu \mathbf{H}=0 .
\end{array}\right.
$$

Here, the vector-functions $\mathbf{E}=\left(E_{1}, E_{2}, E_{3}\right)^{\top}$ and $\mathbf{H}=\left(H_{1}, H_{2}, H_{3}\right)^{\top}$ denote the scattered electric and magnetic fields, $\omega$ is the frequency, and the corresponding

Copyright 2016 by the Tusi Mathematical Research Group.

Received Mar. 31, 2015; Accepted May 12, 2015.

${ }^{*}$ Corresponding author.

2010 Mathematics Subject Classification. Primary 35J25; Secondary 35C15, 47F05.

Keywords. screens, pseudo-Maxwell equations, integral representation, potential theory. 


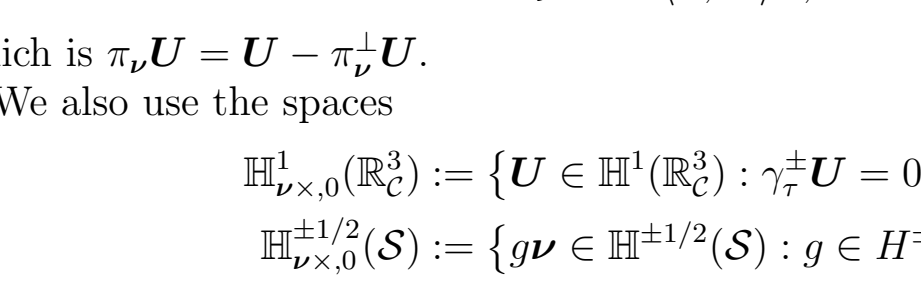

\title{
SCREEN TYPE PROBLEMS FOR ANISOTROPIC PSEUDO-MAXWELL'S EQUATIONS
}

\author{
OTAR CHKADUA,${ }^{1}$ ROLAND DUDUCHAVA,${ }^{2}$ and DAVID KAPANADZE ${ }^{3 *}$ \\ Dedicated to Professor Anthony To-Ming Lau \\ Communicated by Gradimir V. Milovanovic
}

\begin{abstract}
We investigate screen-type boundary value problems for anisotropic pseudo-Maxwell's equations. It is shown that the problems with tangent traces are well posed in tangent Sobolev spaces. The unique solvability result is then obtained by using a potential method and the coercivity result of Costabel for the bilinear form associated with the pseudo-Maxwell's equation.
\end{abstract}

\section{IntRoduction}

The study of boundary value problems in electromagnetism naturally leads us to the pseudo-Maxwell's equations with inherited tangent boundary conditions, which are in some sense nonstandard for the system of elliptic equations (see works of Buffa, Costabel, Christiansen, Dauge, Hazard, Lenoir, Mitrea, Nicaise and others). Indeed, let us consider the time-harmonic Maxwell equations in an anisotropic domain $\Omega \subset \mathbb{R}^{3}$,

$$
\left\{\begin{array}{l}
\operatorname{curl} \mathbf{H}+i \omega \varepsilon \mathbf{E}=0, \\
\operatorname{curl} \mathbf{E}-i \omega \mu \mathbf{H}=0 .
\end{array}\right.
$$

Here, the vector-functions $\mathbf{E}=\left(E_{1}, E_{2}, E_{3}\right)^{\top}$ and $\mathbf{H}=\left(H_{1}, H_{2}, H_{3}\right)^{\top}$ denote the scattered electric and magnetic fields, $\omega$ is the frequency, and the corresponding

Copyright 2016 by the Tusi Mathematical Research Group.

Received Mar. 31, 2015; Accepted May 12, 2015.

${ }^{*}$ Corresponding author.

2010 Mathematics Subject Classification. Primary 35J25; Secondary 35C15, 47F05.

Keywords. screens, pseudo-Maxwell equations, integral representation, potential theory. 


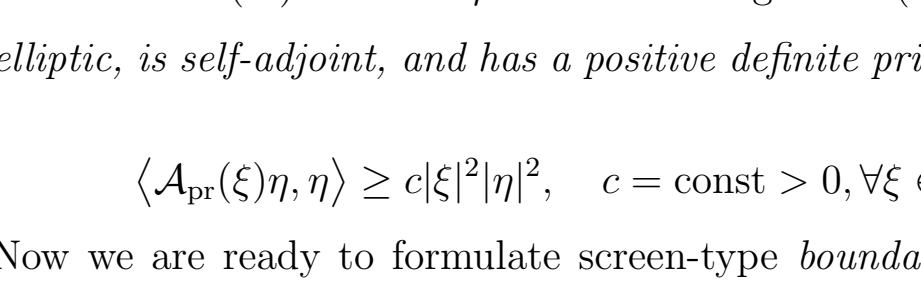

\title{
SCREEN TYPE PROBLEMS FOR ANISOTROPIC PSEUDO-MAXWELL'S EQUATIONS
}

\author{
OTAR CHKADUA,${ }^{1}$ ROLAND DUDUCHAVA,${ }^{2}$ and DAVID KAPANADZE ${ }^{3 *}$ \\ Dedicated to Professor Anthony To-Ming Lau \\ Communicated by Gradimir V. Milovanovic
}

\begin{abstract}
We investigate screen-type boundary value problems for anisotropic pseudo-Maxwell's equations. It is shown that the problems with tangent traces are well posed in tangent Sobolev spaces. The unique solvability result is then obtained by using a potential method and the coercivity result of Costabel for the bilinear form associated with the pseudo-Maxwell's equation.
\end{abstract}

\section{IntRoduction}

The study of boundary value problems in electromagnetism naturally leads us to the pseudo-Maxwell's equations with inherited tangent boundary conditions, which are in some sense nonstandard for the system of elliptic equations (see works of Buffa, Costabel, Christiansen, Dauge, Hazard, Lenoir, Mitrea, Nicaise and others). Indeed, let us consider the time-harmonic Maxwell equations in an anisotropic domain $\Omega \subset \mathbb{R}^{3}$,

$$
\left\{\begin{array}{l}
\operatorname{curl} \mathbf{H}+i \omega \varepsilon \mathbf{E}=0, \\
\operatorname{curl} \mathbf{E}-i \omega \mu \mathbf{H}=0 .
\end{array}\right.
$$

Here, the vector-functions $\mathbf{E}=\left(E_{1}, E_{2}, E_{3}\right)^{\top}$ and $\mathbf{H}=\left(H_{1}, H_{2}, H_{3}\right)^{\top}$ denote the scattered electric and magnetic fields, $\omega$ is the frequency, and the corresponding

Copyright 2016 by the Tusi Mathematical Research Group.

Received Mar. 31, 2015; Accepted May 12, 2015.

${ }^{*}$ Corresponding author.

2010 Mathematics Subject Classification. Primary 35J25; Secondary 35C15, 47F05.

Keywords. screens, pseudo-Maxwell equations, integral representation, potential theory. 


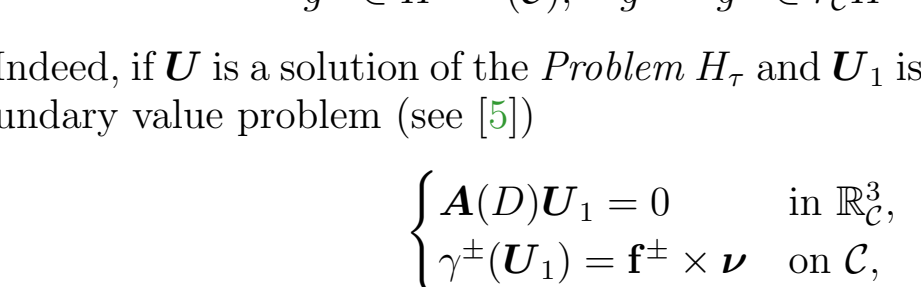

\title{
SCREEN TYPE PROBLEMS FOR ANISOTROPIC PSEUDO-MAXWELL'S EQUATIONS
}

\author{
OTAR CHKADUA,${ }^{1}$ ROLAND DUDUCHAVA,${ }^{2}$ and DAVID KAPANADZE ${ }^{3 *}$ \\ Dedicated to Professor Anthony To-Ming Lau \\ Communicated by Gradimir V. Milovanovic
}

\begin{abstract}
We investigate screen-type boundary value problems for anisotropic pseudo-Maxwell's equations. It is shown that the problems with tangent traces are well posed in tangent Sobolev spaces. The unique solvability result is then obtained by using a potential method and the coercivity result of Costabel for the bilinear form associated with the pseudo-Maxwell's equation.
\end{abstract}

\section{IntRoduction}

The study of boundary value problems in electromagnetism naturally leads us to the pseudo-Maxwell's equations with inherited tangent boundary conditions, which are in some sense nonstandard for the system of elliptic equations (see works of Buffa, Costabel, Christiansen, Dauge, Hazard, Lenoir, Mitrea, Nicaise and others). Indeed, let us consider the time-harmonic Maxwell equations in an anisotropic domain $\Omega \subset \mathbb{R}^{3}$,

$$
\left\{\begin{array}{l}
\operatorname{curl} \mathbf{H}+i \omega \varepsilon \mathbf{E}=0, \\
\operatorname{curl} \mathbf{E}-i \omega \mu \mathbf{H}=0 .
\end{array}\right.
$$

Here, the vector-functions $\mathbf{E}=\left(E_{1}, E_{2}, E_{3}\right)^{\top}$ and $\mathbf{H}=\left(H_{1}, H_{2}, H_{3}\right)^{\top}$ denote the scattered electric and magnetic fields, $\omega$ is the frequency, and the corresponding

Copyright 2016 by the Tusi Mathematical Research Group.

Received Mar. 31, 2015; Accepted May 12, 2015.

${ }^{*}$ Corresponding author.

2010 Mathematics Subject Classification. Primary 35J25; Secondary 35C15, 47F05.

Keywords. screens, pseudo-Maxwell equations, integral representation, potential theory. 


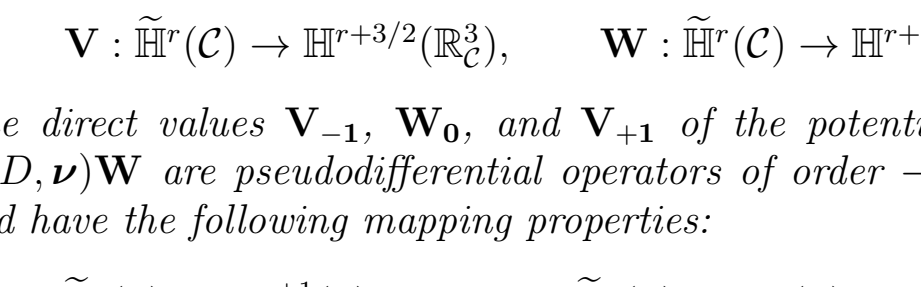

\title{
SCREEN TYPE PROBLEMS FOR ANISOTROPIC PSEUDO-MAXWELL'S EQUATIONS
}

\author{
OTAR CHKADUA,${ }^{1}$ ROLAND DUDUCHAVA,${ }^{2}$ and DAVID KAPANADZE ${ }^{3 *}$ \\ Dedicated to Professor Anthony To-Ming Lau \\ Communicated by Gradimir V. Milovanovic
}

\begin{abstract}
We investigate screen-type boundary value problems for anisotropic pseudo-Maxwell's equations. It is shown that the problems with tangent traces are well posed in tangent Sobolev spaces. The unique solvability result is then obtained by using a potential method and the coercivity result of Costabel for the bilinear form associated with the pseudo-Maxwell's equation.
\end{abstract}

\section{IntRoduction}

The study of boundary value problems in electromagnetism naturally leads us to the pseudo-Maxwell's equations with inherited tangent boundary conditions, which are in some sense nonstandard for the system of elliptic equations (see works of Buffa, Costabel, Christiansen, Dauge, Hazard, Lenoir, Mitrea, Nicaise and others). Indeed, let us consider the time-harmonic Maxwell equations in an anisotropic domain $\Omega \subset \mathbb{R}^{3}$,

$$
\left\{\begin{array}{l}
\operatorname{curl} \mathbf{H}+i \omega \varepsilon \mathbf{E}=0, \\
\operatorname{curl} \mathbf{E}-i \omega \mu \mathbf{H}=0 .
\end{array}\right.
$$

Here, the vector-functions $\mathbf{E}=\left(E_{1}, E_{2}, E_{3}\right)^{\top}$ and $\mathbf{H}=\left(H_{1}, H_{2}, H_{3}\right)^{\top}$ denote the scattered electric and magnetic fields, $\omega$ is the frequency, and the corresponding

Copyright 2016 by the Tusi Mathematical Research Group.

Received Mar. 31, 2015; Accepted May 12, 2015.

${ }^{*}$ Corresponding author.

2010 Mathematics Subject Classification. Primary 35J25; Secondary 35C15, 47F05.

Keywords. screens, pseudo-Maxwell equations, integral representation, potential theory. 


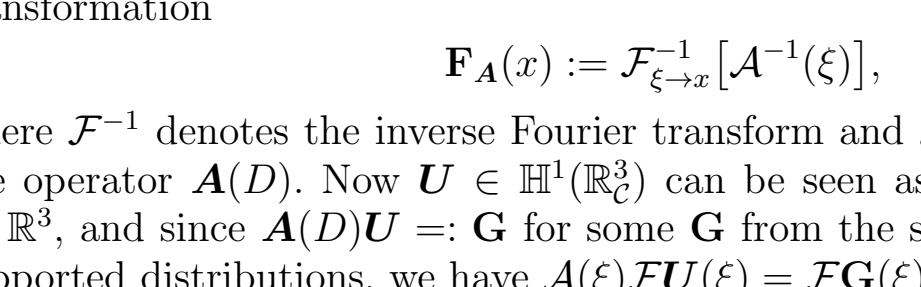

\title{
SCREEN TYPE PROBLEMS FOR ANISOTROPIC PSEUDO-MAXWELL'S EQUATIONS
}

\author{
OTAR CHKADUA,${ }^{1}$ ROLAND DUDUCHAVA,${ }^{2}$ and DAVID KAPANADZE ${ }^{3 *}$ \\ Dedicated to Professor Anthony To-Ming Lau \\ Communicated by Gradimir V. Milovanovic
}

\begin{abstract}
We investigate screen-type boundary value problems for anisotropic pseudo-Maxwell's equations. It is shown that the problems with tangent traces are well posed in tangent Sobolev spaces. The unique solvability result is then obtained by using a potential method and the coercivity result of Costabel for the bilinear form associated with the pseudo-Maxwell's equation.
\end{abstract}

\section{IntRoduction}

The study of boundary value problems in electromagnetism naturally leads us to the pseudo-Maxwell's equations with inherited tangent boundary conditions, which are in some sense nonstandard for the system of elliptic equations (see works of Buffa, Costabel, Christiansen, Dauge, Hazard, Lenoir, Mitrea, Nicaise and others). Indeed, let us consider the time-harmonic Maxwell equations in an anisotropic domain $\Omega \subset \mathbb{R}^{3}$,

$$
\left\{\begin{array}{l}
\operatorname{curl} \mathbf{H}+i \omega \varepsilon \mathbf{E}=0, \\
\operatorname{curl} \mathbf{E}-i \omega \mu \mathbf{H}=0 .
\end{array}\right.
$$

Here, the vector-functions $\mathbf{E}=\left(E_{1}, E_{2}, E_{3}\right)^{\top}$ and $\mathbf{H}=\left(H_{1}, H_{2}, H_{3}\right)^{\top}$ denote the scattered electric and magnetic fields, $\omega$ is the frequency, and the corresponding

Copyright 2016 by the Tusi Mathematical Research Group.

Received Mar. 31, 2015; Accepted May 12, 2015.

${ }^{*}$ Corresponding author.

2010 Mathematics Subject Classification. Primary 35J25; Secondary 35C15, 47F05.

Keywords. screens, pseudo-Maxwell equations, integral representation, potential theory. 


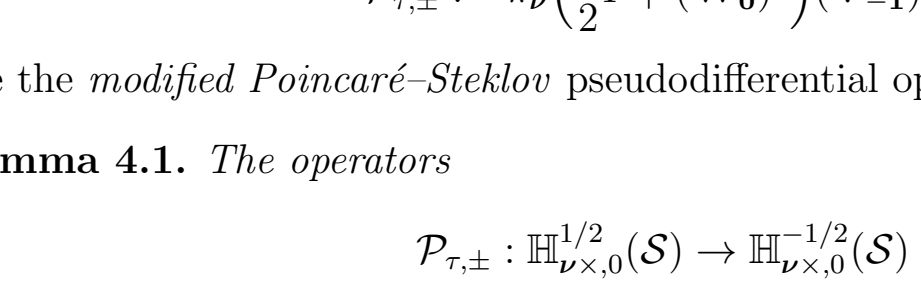

\title{
SCREEN TYPE PROBLEMS FOR ANISOTROPIC PSEUDO-MAXWELL'S EQUATIONS
}

\author{
OTAR CHKADUA,${ }^{1}$ ROLAND DUDUCHAVA,${ }^{2}$ and DAVID KAPANADZE ${ }^{3 *}$ \\ Dedicated to Professor Anthony To-Ming Lau \\ Communicated by Gradimir V. Milovanovic
}

\begin{abstract}
We investigate screen-type boundary value problems for anisotropic pseudo-Maxwell's equations. It is shown that the problems with tangent traces are well posed in tangent Sobolev spaces. The unique solvability result is then obtained by using a potential method and the coercivity result of Costabel for the bilinear form associated with the pseudo-Maxwell's equation.
\end{abstract}

\section{IntRoduction}

The study of boundary value problems in electromagnetism naturally leads us to the pseudo-Maxwell's equations with inherited tangent boundary conditions, which are in some sense nonstandard for the system of elliptic equations (see works of Buffa, Costabel, Christiansen, Dauge, Hazard, Lenoir, Mitrea, Nicaise and others). Indeed, let us consider the time-harmonic Maxwell equations in an anisotropic domain $\Omega \subset \mathbb{R}^{3}$,

$$
\left\{\begin{array}{l}
\operatorname{curl} \mathbf{H}+i \omega \varepsilon \mathbf{E}=0, \\
\operatorname{curl} \mathbf{E}-i \omega \mu \mathbf{H}=0 .
\end{array}\right.
$$

Here, the vector-functions $\mathbf{E}=\left(E_{1}, E_{2}, E_{3}\right)^{\top}$ and $\mathbf{H}=\left(H_{1}, H_{2}, H_{3}\right)^{\top}$ denote the scattered electric and magnetic fields, $\omega$ is the frequency, and the corresponding

Copyright 2016 by the Tusi Mathematical Research Group.

Received Mar. 31, 2015; Accepted May 12, 2015.

${ }^{*}$ Corresponding author.

2010 Mathematics Subject Classification. Primary 35J25; Secondary 35C15, 47F05.

Keywords. screens, pseudo-Maxwell equations, integral representation, potential theory. 


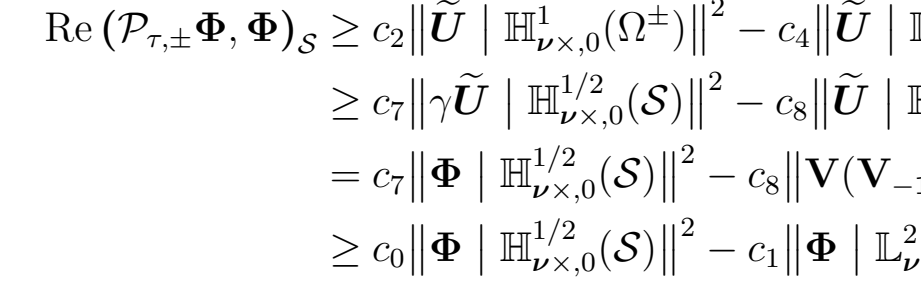

\title{
SCREEN TYPE PROBLEMS FOR ANISOTROPIC PSEUDO-MAXWELL'S EQUATIONS
}

\author{
OTAR CHKADUA,${ }^{1}$ ROLAND DUDUCHAVA,${ }^{2}$ and DAVID KAPANADZE ${ }^{3 *}$ \\ Dedicated to Professor Anthony To-Ming Lau \\ Communicated by Gradimir V. Milovanovic
}

\begin{abstract}
We investigate screen-type boundary value problems for anisotropic pseudo-Maxwell's equations. It is shown that the problems with tangent traces are well posed in tangent Sobolev spaces. The unique solvability result is then obtained by using a potential method and the coercivity result of Costabel for the bilinear form associated with the pseudo-Maxwell's equation.
\end{abstract}

\section{IntRoduction}

The study of boundary value problems in electromagnetism naturally leads us to the pseudo-Maxwell's equations with inherited tangent boundary conditions, which are in some sense nonstandard for the system of elliptic equations (see works of Buffa, Costabel, Christiansen, Dauge, Hazard, Lenoir, Mitrea, Nicaise and others). Indeed, let us consider the time-harmonic Maxwell equations in an anisotropic domain $\Omega \subset \mathbb{R}^{3}$,

$$
\left\{\begin{array}{l}
\operatorname{curl} \mathbf{H}+i \omega \varepsilon \mathbf{E}=0, \\
\operatorname{curl} \mathbf{E}-i \omega \mu \mathbf{H}=0 .
\end{array}\right.
$$

Here, the vector-functions $\mathbf{E}=\left(E_{1}, E_{2}, E_{3}\right)^{\top}$ and $\mathbf{H}=\left(H_{1}, H_{2}, H_{3}\right)^{\top}$ denote the scattered electric and magnetic fields, $\omega$ is the frequency, and the corresponding

Copyright 2016 by the Tusi Mathematical Research Group.

Received Mar. 31, 2015; Accepted May 12, 2015.

${ }^{*}$ Corresponding author.

2010 Mathematics Subject Classification. Primary 35J25; Secondary 35C15, 47F05.

Keywords. screens, pseudo-Maxwell equations, integral representation, potential theory. 


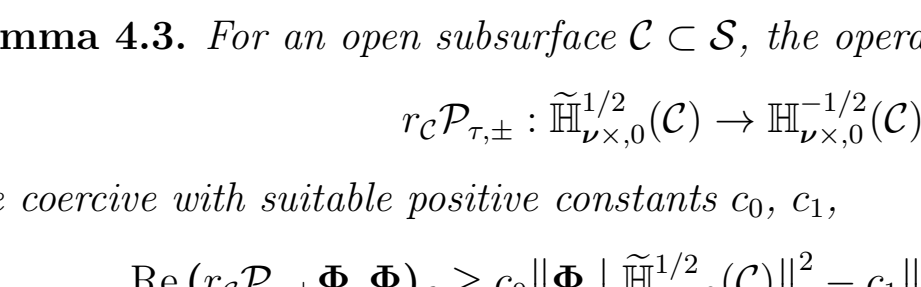

\title{
SCREEN TYPE PROBLEMS FOR ANISOTROPIC PSEUDO-MAXWELL'S EQUATIONS
}

\author{
OTAR CHKADUA,${ }^{1}$ ROLAND DUDUCHAVA,${ }^{2}$ and DAVID KAPANADZE ${ }^{3 *}$ \\ Dedicated to Professor Anthony To-Ming Lau \\ Communicated by Gradimir V. Milovanovic
}

\begin{abstract}
We investigate screen-type boundary value problems for anisotropic pseudo-Maxwell's equations. It is shown that the problems with tangent traces are well posed in tangent Sobolev spaces. The unique solvability result is then obtained by using a potential method and the coercivity result of Costabel for the bilinear form associated with the pseudo-Maxwell's equation.
\end{abstract}

\section{IntRoduction}

The study of boundary value problems in electromagnetism naturally leads us to the pseudo-Maxwell's equations with inherited tangent boundary conditions, which are in some sense nonstandard for the system of elliptic equations (see works of Buffa, Costabel, Christiansen, Dauge, Hazard, Lenoir, Mitrea, Nicaise and others). Indeed, let us consider the time-harmonic Maxwell equations in an anisotropic domain $\Omega \subset \mathbb{R}^{3}$,

$$
\left\{\begin{array}{l}
\operatorname{curl} \mathbf{H}+i \omega \varepsilon \mathbf{E}=0, \\
\operatorname{curl} \mathbf{E}-i \omega \mu \mathbf{H}=0 .
\end{array}\right.
$$

Here, the vector-functions $\mathbf{E}=\left(E_{1}, E_{2}, E_{3}\right)^{\top}$ and $\mathbf{H}=\left(H_{1}, H_{2}, H_{3}\right)^{\top}$ denote the scattered electric and magnetic fields, $\omega$ is the frequency, and the corresponding

Copyright 2016 by the Tusi Mathematical Research Group.

Received Mar. 31, 2015; Accepted May 12, 2015.

${ }^{*}$ Corresponding author.

2010 Mathematics Subject Classification. Primary 35J25; Secondary 35C15, 47F05.

Keywords. screens, pseudo-Maxwell equations, integral representation, potential theory. 


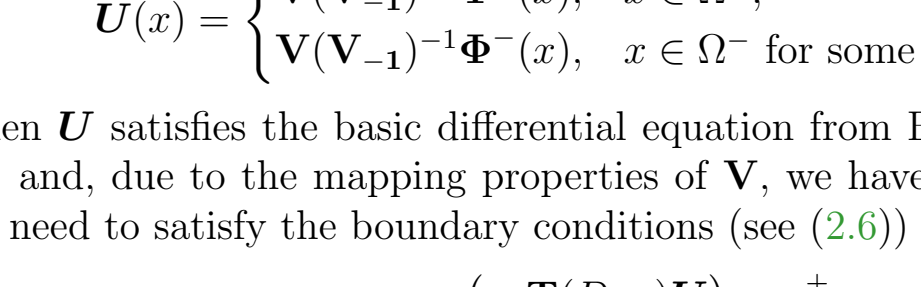

\title{
SCREEN TYPE PROBLEMS FOR ANISOTROPIC PSEUDO-MAXWELL'S EQUATIONS
}

\author{
OTAR CHKADUA,${ }^{1}$ ROLAND DUDUCHAVA,${ }^{2}$ and DAVID KAPANADZE ${ }^{3 *}$ \\ Dedicated to Professor Anthony To-Ming Lau \\ Communicated by Gradimir V. Milovanovic
}

\begin{abstract}
We investigate screen-type boundary value problems for anisotropic pseudo-Maxwell's equations. It is shown that the problems with tangent traces are well posed in tangent Sobolev spaces. The unique solvability result is then obtained by using a potential method and the coercivity result of Costabel for the bilinear form associated with the pseudo-Maxwell's equation.
\end{abstract}

\section{IntRoduction}

The study of boundary value problems in electromagnetism naturally leads us to the pseudo-Maxwell's equations with inherited tangent boundary conditions, which are in some sense nonstandard for the system of elliptic equations (see works of Buffa, Costabel, Christiansen, Dauge, Hazard, Lenoir, Mitrea, Nicaise and others). Indeed, let us consider the time-harmonic Maxwell equations in an anisotropic domain $\Omega \subset \mathbb{R}^{3}$,

$$
\left\{\begin{array}{l}
\operatorname{curl} \mathbf{H}+i \omega \varepsilon \mathbf{E}=0, \\
\operatorname{curl} \mathbf{E}-i \omega \mu \mathbf{H}=0 .
\end{array}\right.
$$

Here, the vector-functions $\mathbf{E}=\left(E_{1}, E_{2}, E_{3}\right)^{\top}$ and $\mathbf{H}=\left(H_{1}, H_{2}, H_{3}\right)^{\top}$ denote the scattered electric and magnetic fields, $\omega$ is the frequency, and the corresponding

Copyright 2016 by the Tusi Mathematical Research Group.

Received Mar. 31, 2015; Accepted May 12, 2015.

${ }^{*}$ Corresponding author.

2010 Mathematics Subject Classification. Primary 35J25; Secondary 35C15, 47F05.

Keywords. screens, pseudo-Maxwell equations, integral representation, potential theory. 


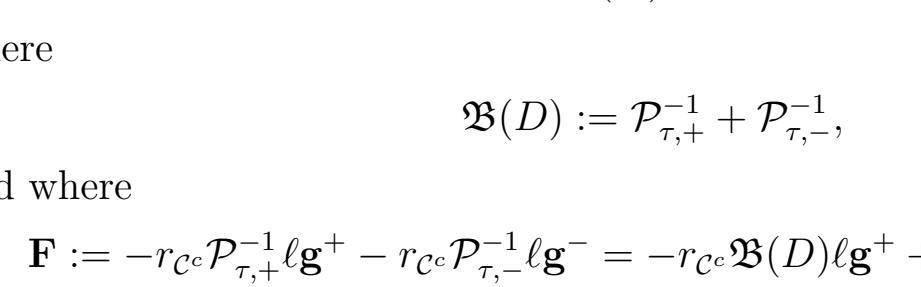

\title{
SCREEN TYPE PROBLEMS FOR ANISOTROPIC PSEUDO-MAXWELL'S EQUATIONS
}

\author{
OTAR CHKADUA,${ }^{1}$ ROLAND DUDUCHAVA,${ }^{2}$ and DAVID KAPANADZE ${ }^{3 *}$ \\ Dedicated to Professor Anthony To-Ming Lau \\ Communicated by Gradimir V. Milovanovic
}

\begin{abstract}
We investigate screen-type boundary value problems for anisotropic pseudo-Maxwell's equations. It is shown that the problems with tangent traces are well posed in tangent Sobolev spaces. The unique solvability result is then obtained by using a potential method and the coercivity result of Costabel for the bilinear form associated with the pseudo-Maxwell's equation.
\end{abstract}

\section{IntRoduction}

The study of boundary value problems in electromagnetism naturally leads us to the pseudo-Maxwell's equations with inherited tangent boundary conditions, which are in some sense nonstandard for the system of elliptic equations (see works of Buffa, Costabel, Christiansen, Dauge, Hazard, Lenoir, Mitrea, Nicaise and others). Indeed, let us consider the time-harmonic Maxwell equations in an anisotropic domain $\Omega \subset \mathbb{R}^{3}$,

$$
\left\{\begin{array}{l}
\operatorname{curl} \mathbf{H}+i \omega \varepsilon \mathbf{E}=0, \\
\operatorname{curl} \mathbf{E}-i \omega \mu \mathbf{H}=0 .
\end{array}\right.
$$

Here, the vector-functions $\mathbf{E}=\left(E_{1}, E_{2}, E_{3}\right)^{\top}$ and $\mathbf{H}=\left(H_{1}, H_{2}, H_{3}\right)^{\top}$ denote the scattered electric and magnetic fields, $\omega$ is the frequency, and the corresponding

Copyright 2016 by the Tusi Mathematical Research Group.

Received Mar. 31, 2015; Accepted May 12, 2015.

${ }^{*}$ Corresponding author.

2010 Mathematics Subject Classification. Primary 35J25; Secondary 35C15, 47F05.

Keywords. screens, pseudo-Maxwell equations, integral representation, potential theory. 


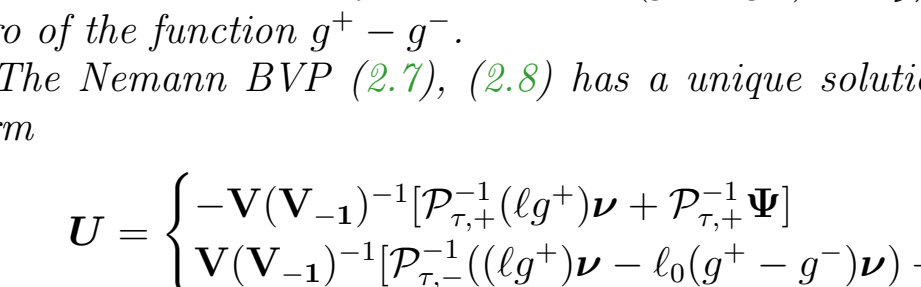

\title{
SCREEN TYPE PROBLEMS FOR ANISOTROPIC PSEUDO-MAXWELL'S EQUATIONS
}

\author{
OTAR CHKADUA,${ }^{1}$ ROLAND DUDUCHAVA,${ }^{2}$ and DAVID KAPANADZE ${ }^{3 *}$ \\ Dedicated to Professor Anthony To-Ming Lau \\ Communicated by Gradimir V. Milovanovic
}

\begin{abstract}
We investigate screen-type boundary value problems for anisotropic pseudo-Maxwell's equations. It is shown that the problems with tangent traces are well posed in tangent Sobolev spaces. The unique solvability result is then obtained by using a potential method and the coercivity result of Costabel for the bilinear form associated with the pseudo-Maxwell's equation.
\end{abstract}

\section{IntRoduction}

The study of boundary value problems in electromagnetism naturally leads us to the pseudo-Maxwell's equations with inherited tangent boundary conditions, which are in some sense nonstandard for the system of elliptic equations (see works of Buffa, Costabel, Christiansen, Dauge, Hazard, Lenoir, Mitrea, Nicaise and others). Indeed, let us consider the time-harmonic Maxwell equations in an anisotropic domain $\Omega \subset \mathbb{R}^{3}$,

$$
\left\{\begin{array}{l}
\operatorname{curl} \mathbf{H}+i \omega \varepsilon \mathbf{E}=0, \\
\operatorname{curl} \mathbf{E}-i \omega \mu \mathbf{H}=0 .
\end{array}\right.
$$

Here, the vector-functions $\mathbf{E}=\left(E_{1}, E_{2}, E_{3}\right)^{\top}$ and $\mathbf{H}=\left(H_{1}, H_{2}, H_{3}\right)^{\top}$ denote the scattered electric and magnetic fields, $\omega$ is the frequency, and the corresponding

Copyright 2016 by the Tusi Mathematical Research Group.

Received Mar. 31, 2015; Accepted May 12, 2015.

${ }^{*}$ Corresponding author.

2010 Mathematics Subject Classification. Primary 35J25; Secondary 35C15, 47F05.

Keywords. screens, pseudo-Maxwell equations, integral representation, potential theory. 


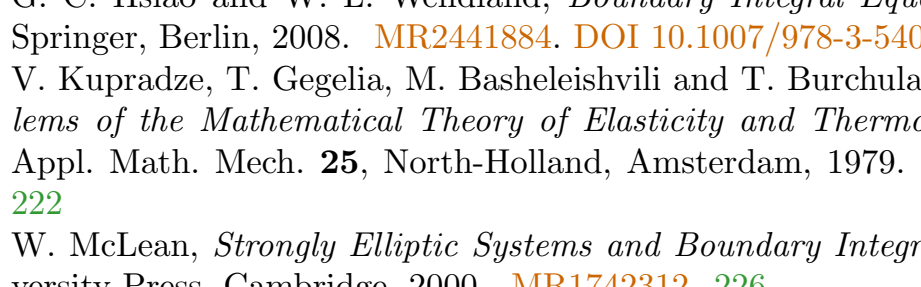

\title{
SCREEN TYPE PROBLEMS FOR ANISOTROPIC PSEUDO-MAXWELL'S EQUATIONS
}

\author{
OTAR CHKADUA,${ }^{1}$ ROLAND DUDUCHAVA,${ }^{2}$ and DAVID KAPANADZE ${ }^{3 *}$ \\ Dedicated to Professor Anthony To-Ming Lau \\ Communicated by Gradimir V. Milovanovic
}

\begin{abstract}
We investigate screen-type boundary value problems for anisotropic pseudo-Maxwell's equations. It is shown that the problems with tangent traces are well posed in tangent Sobolev spaces. The unique solvability result is then obtained by using a potential method and the coercivity result of Costabel for the bilinear form associated with the pseudo-Maxwell's equation.
\end{abstract}

\section{IntRoduction}

The study of boundary value problems in electromagnetism naturally leads us to the pseudo-Maxwell's equations with inherited tangent boundary conditions, which are in some sense nonstandard for the system of elliptic equations (see works of Buffa, Costabel, Christiansen, Dauge, Hazard, Lenoir, Mitrea, Nicaise and others). Indeed, let us consider the time-harmonic Maxwell equations in an anisotropic domain $\Omega \subset \mathbb{R}^{3}$,

$$
\left\{\begin{array}{l}
\operatorname{curl} \mathbf{H}+i \omega \varepsilon \mathbf{E}=0, \\
\operatorname{curl} \mathbf{E}-i \omega \mu \mathbf{H}=0 .
\end{array}\right.
$$

Here, the vector-functions $\mathbf{E}=\left(E_{1}, E_{2}, E_{3}\right)^{\top}$ and $\mathbf{H}=\left(H_{1}, H_{2}, H_{3}\right)^{\top}$ denote the scattered electric and magnetic fields, $\omega$ is the frequency, and the corresponding

Copyright 2016 by the Tusi Mathematical Research Group.

Received Mar. 31, 2015; Accepted May 12, 2015.

${ }^{*}$ Corresponding author.

2010 Mathematics Subject Classification. Primary 35J25; Secondary 35C15, 47F05.

Keywords. screens, pseudo-Maxwell equations, integral representation, potential theory. 